Article

\title{
An Analysis of Vulnerable Road Users Overtaking Maneuver along the Urban Road
}

\author{
Manh Dung Vu ${ }^{1, *}$, Hirofumi Aoki ${ }^{2, *}$, Tatsuya Suzuki ${ }^{1}$, Sueharu Nagiri ${ }^{2}$, Quy Hung Nguyen Van ${ }^{3}$, \\ Shouji Itou ${ }^{3}$ and Akira Hattori ${ }^{3}$ \\ 1 Department of Mechanical Systems Engineering, Nagoya University, Furo-cho, Chikusa Ward, \\ Nagoya 464-8603, Japan; t_suzuki@nuem.nagoya-u.ac.jp \\ 2 Institute of Innovation for Future Society, Nagoya University, Furo-cho, Chikusa Ward, \\ Nagoya 464-8601, Japan; nagiri@coi.nagoya-u.ac.jp \\ 3 Toyota Motor Corporation, Higashi-Fuji Technical Center, 1200 Mishuku, Susono 410-1193, Japan; \\ vanquyhung_nguyen@mail.toyota.co.jp (Q.H.N.V.); shoji_i@mail.toyota.co.jp (S.I.); \\ akira_hattori@mail.toyota.co.jp (A.H.) \\ * Correspondence: vu.manh.dung@c.mbox.nagoya-u.ac.jp (M.D.V.); hiro.aoki@nagoya-u.jp (H.A.); \\ Tel.: +81-80-7895-6050 (M.D.V.)
}

check for updates

Citation: Vu, M.D.; Aoki, H.; Suzuki, T.; Nagiri, S.; Nguyen Van, Q.H.; Itou, S.; Hattori, A. An Analysis of Vulnerable Road Users Overtaking Maneuver along the Urban Road. Appl. Sci. 2021, 11, 6361. https:// doi.org/10.3390/app11146361

Academic Editor: Marco Guerrieri

Received: 22 June 2021

Accepted: 5 July 2021

Published: 9 July 2021

Publisher's Note: MDPI stays neutral with regard to jurisdictional claims in published maps and institutional affiliations.

Copyright: (c) 2021 by the authors. Licensee MDPI, Basel, Switzerland. This article is an open access article distributed under the terms and conditions of the Creative Commons Attribution (CC BY) license (https:// creativecommons.org/licenses/by/ $4.0 /)$.
Abstract: This paper discusses driving styles while overtaking a vulnerable road user who moves along the shoulder in urban roads. Based on the data obtained from an experiment in pre-defined conditions (combinations of four main effects: vehicle's initial speed, lane width of the road, vulnerable road users' type, and location in the shoulder) with an immersive driving simulator, we analyzed four different driving styles of drivers while approaching and passing the objects. It is shown that drivers took avoidance maneuvers even if there was no clear risk of collision to vulnerable road users. The results showed that the drivers tended to have a unique perception about the lateral passing gap and overtaking strategy with two worth notice groups: overcaution drivers and reckless drivers. The road characteristic has a statistically significant effect for all types of drivers. Moreover, the effect of the vehicle's initial speed on overtaking strategy and the effect of vulnerable road user location on minimum lateral passing gap are statistically significant. The findings provide some implications for the development of automotive safety systems that can reduce the risk of overtaking maneuvers in urban areas.

Keywords: human factors; behavioral; driving style; driving simulator; overtaking maneuver; collision avoidance; vulnerable road user; road vehicle; Advanced Driver Assistance System

\section{Introduction}

Walking and cycling are popular modes of transportation [1,2]. Pedestrians and cyclists are categorized as vulnerable road users (VRU) because of their lack of protection in case of an accident, which can result in a high risk of injury or even death [3]. In European countries, the percentage of cyclist fatalities on all roads increased from $7 \%$ in 2005 to $8 \%$ in 2014 [4]. In developed countries, pedestrians are involved in 15\% of all fatalities [1]. In Japan, traffic accidents relating to cyclists or pedestrians was roughly $27 \%$ but accounted for more than $52 \%$ of deaths in 2019 [5]. Due to the high possibility of severe collisions in an urban area (55\% of all cyclist fatalities [4]), previous researches focused on the interactions which are commonly occurred at intersections, while drivers are likely to slow down $[1,6,7]$. However, only $27 \%$ of fatalities occurred at intersections or roundabouts on average [4]. Interactions may happen on a straight road while vehicle velocity is much higher than the velocity of cyclists and pedestrians who move on a hard shoulder that is close to the vehicle lane [8,9]. Hence, thorough knowledge of the interaction of drivers with VRU is essential for the development and evaluation of safety systems.

An overtaking maneuver contains four phases: (1) vehicle approaches the vulnerable road user and the driver judge the situation; (2) the driver decides to overtake and starts 
the avoidance; (3) vehicle passes the object and (4) vehicle returns to its own lane [2]. In the approaching phase, drivers have dissimilar behaviors to regulate speed before making overtaking decisions. Two strategies of overtaking were suggested: flying overtaking (in which drivers prefer to keep higher speed in the approaching phase than initial speed), and accelerative overtaking (drivers reduce speed in the approaching phase) [10]. The ratio of the vehicle's minimum speed while approaching VRU to initial speed (RMS) can be used as a metric to distinguish these strategies. For VRU overtaking, the flying overtaking maneuver (RMS is about 1) was not preferred and drivers chose to decelerate to a speed that was lower than the initial speed [11] and RMS is much lower than 1.

A variety of safety metrics has been proposed: minimum distance from the vehicle to object in approaching, steering, passing, returning phase of an overtaking (Comfort Zone Boundary), time to a collision between motorist and VRU or incoming vehicle, vehicle speed at specific timing [2,5,12-17]. Above all, the minimum lateral gap while passing objects (LPG) is definitely a key metric for safety [2]. LPG is influenced by the driver [16], so classification of driver behavior may provide useful information. Bicycle passing laws (1.5 $\mathrm{m}$ in a rural road in some European countries [4]) could influence drivers' habits. Larger lane width could lead to greater LPG as the driver will be less constrained by oncoming or adjacent motor vehicles [12]. Higher vehicle velocity should lead to larger LPG as it reduces time to collision and may cause higher accident risk [12]. LPG also had been found larger in accelerative maneuvers than in flying maneuvers [14].

Overall, LPG and RMS are important indicators for driver behavior in overtaking maneuvers. These indicators are greatly influenced by road configuration, vehicle speed on rural roads. Hence, the influences of urban's infrastructure (fixed lane width, shoulder width with a variation of speed limit) on these indicators are on demand. On the other side, no study has classified driver behavior to rate, train drivers, and provide a guideline in designing safety systems. It is worth noting that safety system warnings and intervention must be accepted by drivers or they won't be put into action [13]. To simplify the prediction of driver's acceptance, we proposed that there are divergent groups of drivers. In our experiment, the drivers drove normally in a normal state without other attractions (using a smartphone ... other road users). Using influential indicators (LPG, RMS) to investigate the driver behavior, we aim to prove the non-identical behavior even in undemanding situations, that must be considered when developing the safety systems.

We hypothesized that in a normal state: there are three types of drivers-reckless, competent, overcaution with non-identical driving styles-aggressive, moderate, conservative, respectively. This study furthered the work of Nagiri et al., in which drivers were divided into two driver groups with differences in the lateral gap when a sedan-type subject vehicle (SV) passing VRU, the minimum speed of SV, and time-to-collision from SV to VRU when the driver took first response [5]. Additional analyses of those two moderate groups revealed the existence of two non-identical driving styles of drivers in a normal state: aggressive and conservative. Our observations of clear differences in driver's decisions among those groups of drivers imply the need for personalized assistance systems to increase the mutual acceptance of drivers.

In this paper, using data from an experiment in a driving simulator, we investigated (1) the distinctive driving styles between different driver groups with regard to VRU overtaking behavior and (2) the influence of initial speed, VRU, and road characteristics on those groups. The outcomes of this study were generalized to offer an overview of driving styles to be considered in the design of Advanced Driver Assistance Systems (ADAS) and Autonomous Vehicle (AV).

\section{Materials and Methods}

\subsection{Participants}

The study involved the Japanese staff of Nagoya University, Japan. Eighteen volunteers (age $54.1 \pm 11.6), 7$ females and 11 males, all having a valid driving license. Their 
participation was approved by the Ethical Review Board based on the regulation of the Institute of Innovation for Future Society.

\subsection{Driving Simulator}

The study was conducted using the immersive driving simulator (DS) with stereoscopic vision at Nagoya University (Figure 1). A realistic cockpit with all necessary equipment was installed on the 6DOF motion platform which is capable of noticing the driver about the generation of acceleration due to the driving operation [18]. The DS used a stereoscopic image on the immersive display where the cabin was located in a square room where the floor and walls were used as screens for projecting $4 \mathrm{~K}$ resolution images of the driving scene. The image projected on the screen is a stereo image that takes into account the parallax of the left and right eyes, and by using a head tracking system that measures the position and orientation of the person's head, the image is displayed from a viewpoint that matches the position of the person. The immersive display offers binocular parallax stereoscopic vision and motion parallax stereoscopic vision, and faithfully reproduces the sense of depth and distance [19]. With these unique functions, the DS can provide a driving environment that seems more natural than any existing conventional DS.

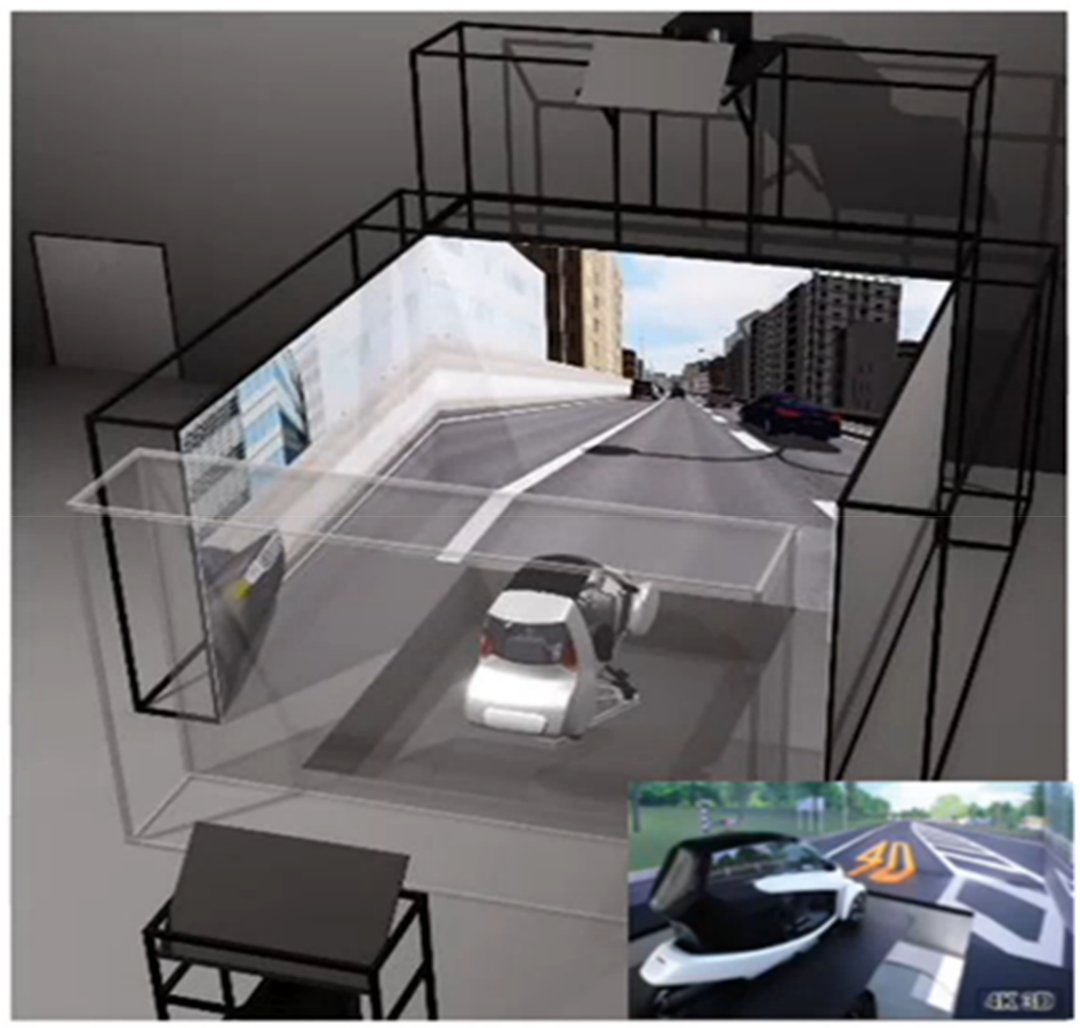

Figure 1. The Immersive Driving Simulator.

\subsection{Experimental Setup}

The trial took place in an urban environment where static elements such as buildings and plants as well as dynamic elements such as other cars, cyclists, and pedestrians were simulated in the DS as similar as possible to a Japanese street in the cityscape. The driving environment included a trial and eight drives on two different straight roads $\mathrm{A}$ and $\mathrm{B}$. The length of each road is $5 \mathrm{~km}$. There are intersections after each $100 \mathrm{~m}$, without traffic lights but the roads are a priority. Using a sedan-type subject vehicle (SV), the participant drove four drives on each road with four initial speeds (30, 40,50, and $60 \mathrm{~km} / \mathrm{h})$. Road A is a 2-lane road with a centerline, the lane width is $3.5 \mathrm{~m}$, and the shoulder is $1 \mathrm{~m}$. Road $B$ is a narrower road without a divider, the lane width is set at $3.0 \mathrm{~m}$, and the shoulder width is $0.75 \mathrm{~m}$. There was an oncoming vehicle (OCV)-sedan-type that was standing still 
until the SV reach the desired value. Each road consists of 18 overtaking maneuvers of VRU with a variation of VRU types (3), VRU location (2), and OCV location (3: near or far to virtual reaching point of subject vehicle and VRU and without OCV). All overtaking maneuvers took place after the intersections in the straight street with good visibility. Three types of VRU: child, adult, cyclist appeared from the left of the intersection with different constant speeds $(4,5$, and $10 \mathrm{~km} / \mathrm{h}$, respectively), then moving along the direction of SV. The location of VRUs was maintained on the edge or the middle of the shoulder. Taking into account the assumptions about the widths of the pedestrian and the vehicle $(0.6 \mathrm{~m}$ and $1.8 \mathrm{~m}$, respectively), the lateral distance between SV and VRU is $0.55 \mathrm{~m}$ on road A and $0.3 \mathrm{~m}$ on road B at the beginning of each trial. As this value is quite narrow, the driver will likely perform some lateral movement.

Table 1 presented a brief overview of experimental conditions. Overall, there were 4 drives on road A, 4 drives on road B, each with a fixed initial speed of $30,40,50$, or $60 \mathrm{~km} / \mathrm{h}$. The VRU's type, location, and OCV's location were varied so that there were 18 different situations in each drive and 144 situations in total per driver.

Table 1. Experimental conditions.

\begin{tabular}{|c|c|c|c|c|c|}
\hline \multicolumn{2}{|r|}{ Condition } & \multicolumn{4}{|c|}{ Details } \\
\hline \multirow[t]{2}{*}{ Road } & Lane width $[\mathrm{m}]$ & \multicolumn{2}{|c|}{3.0} & \multicolumn{2}{|c|}{3.5} \\
\hline & Shoulder [m] & \multicolumn{2}{|c|}{0.75} & \multicolumn{2}{|c|}{1.0} \\
\hline SV & Initial speed $[\mathrm{km} / \mathrm{h}]$ & 30 & 40 & 50 & 60 \\
\hline \multirow{2}{*}{ VRU } & Type & Child & \multicolumn{2}{|c|}{ Adult } & Cyclist \\
\hline & Location & On the edg & ricle lane & \multicolumn{2}{|c|}{ In the middle of the shoulder } \\
\hline OCV & Location & No & & & Near \\
\hline
\end{tabular}

\subsection{Experimental Procedure}

Before the experiment, each participant was provided with general information about the precautions and the tasks they had to perform. Then, they were requested to fill in a questionnaire to acquire demographic data (e.g., age, gender), confirm their general mental state and their understanding of the information provided. Volunteers were informed and consented to the use of collected data.

The subjects practiced in a trial run, where they were asked to drive (steer the wheel and/or accelerate, decelerate, brake) after hearing a ping pong sound. There were automatic driving phases between each overtaking maneuver so that the initial value of SV's velocity and the lateral distance between SV and VRU were always in control conditions (Figure 2). After getting used to the experiment, the participant took on eight drives in random order.

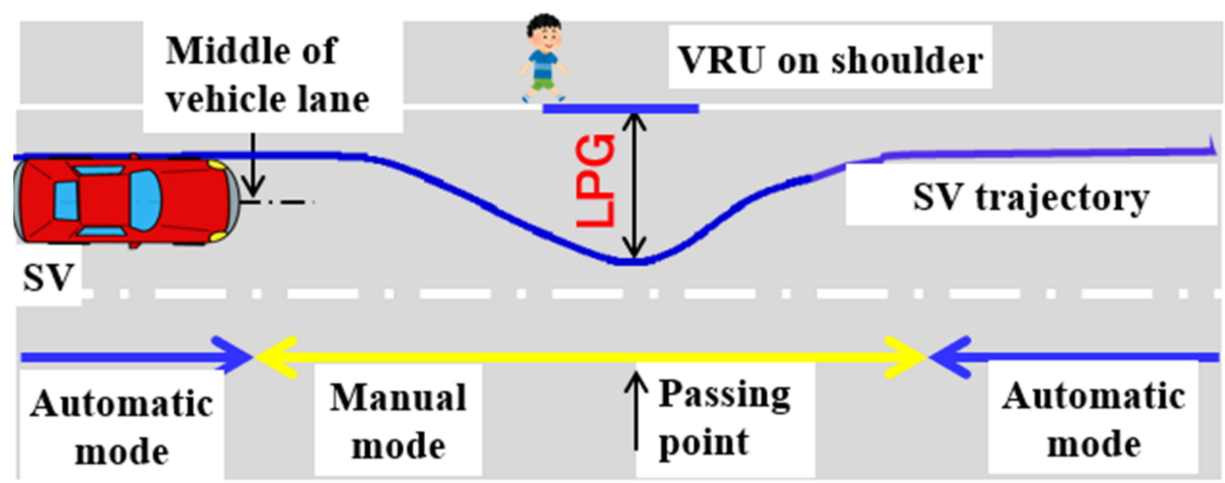

Figure 2. Experimental procedure of a VRU overtaking maneuver. 
An image of the experiment is reported in Figure 3 that shows the VRU traveling on the left side, in the middle of the shoulder. During the overtaking maneuvers (in manual mode), the drivers could decide their speed and gap to the VRU. There was a break time of five minutes between each drive. The experiment time is about 1.0 to $1.5 \mathrm{~h}$.

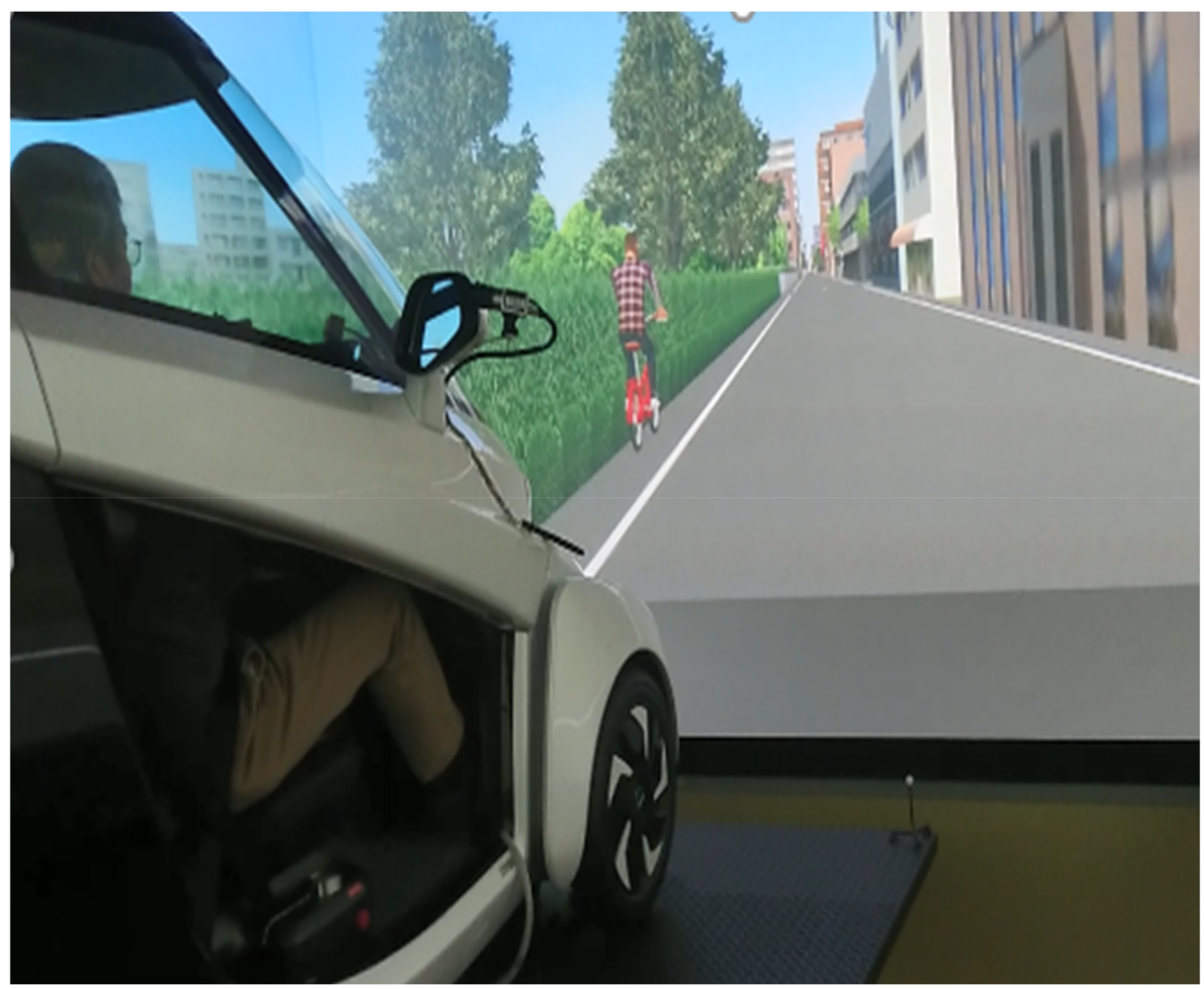

Figure 3. An example of the scene before the VRU's overtaking maneuver.

\subsection{Data Analysis}

Participants were categorized into groups with regard to their driving styles. The differences between driving styles would be visualized by the sample means and $95 \% \mathrm{CI}$ of population means of LPG and RMS.

To study the interaction effects of a car's initial speed (Is), road's lane width (LW), VRU's type, and location (T and L) on LPG and RMS, the linear mixed-effects models [20] were used. First, full models for each group of drivers which contained factors and their interactions as fixed effects were formed. The random effect was a random intercept within the driver and was assumed to follow a normal distribution with a mean of 0 . The interactions between factors were removed from the full model by a stepwise method using the principle of marginality [21] (in which F-statistics for all marginal terms were computed and compared to drop the unfit from the model while respecting the hierarchy of terms in the model). Starting from the highest-order interaction, if a higher-order interaction was significant, then lower-order interactions and effects would not be dropped from the reduced model. Statistical analyses were conducted using the lmerTest package in RStudio, version 1.3.1093.0. Satterthwaite's method was used for computing the denominator degrees of freedom and F-statistics. The significance level was set to $\alpha=0.05$. Linear mixed models were fit by restricted maximum likelihood (REML) [21].

For further knowledge of the main influence of road's lane width, vehicle's initial speed, VRU type, and location on behavior (LPG, RMS) of each driver's group, the analyses of variance with repeated measures (Repeated Measures ANOVA tests) were conducted with a significance level of 0.05 [22]. The LPG and RMS were confirmed to be approximately normally distributed using Shapiro-Wilk normality test. Mauchly's sphericity test was conducted to validate the sphericity assumption. In case of violation, the degrees of 
freedom were corrected by Greenhouse-Geisser procedure. Tukey's Honest Significant Difference tests (TukeyHSD tests) were used as post hoc tests to assess the significance of differences between pairs of group means [23]. Boxplots were used to envision and compare the LPG and RMS of each group.

An image of the experiment is reported in Figure 3 that shows the VRU traveling on the left side, in the middle of the shoulder. During the overtaking maneuvers (in manual mode), the drivers could decide their speed and gap to the VRU. There was a break time of five minutes between each drive. The experiment time is about 1.0 to $1.5 \mathrm{~h}$.

\section{Results}

As there were researches about the major effect of OCV on driver behavior [2,11,14,17,24], the overtaking maneuvers without OCV will be the focus of this paper. Based on the minimum lateral gap while passing vulnerable road users and overtaking strategy which is represented by the ratio of minimum speed to initial speed, the two groups in [5] were further classified into four groups: type A, type B, type C, type D. Type B, and type C drivers were considered as competent. In which, type B's drivers favored the accelerative overtaking, while type C's drivers chose the opposite strategy. Type A drivers were the overcaution ones, whose LPG were the biggest and decelerated in all situations. On the opposite, type D drivers were reckless in their driving style: never slowed down and performed the smallest LPG to VRU. In 18 drivers, the number of drivers in type A, type B, type C, and type D were $2(11.1 \%), 7(38.9 \%), 6(33.3 \%)$, and $3(16.7 \%)$, respectively. No female driver was found in type A. Only 1 female driver was in type B. $3 / 8$ drivers (37.5\%) in type $\mathrm{C}$ and $1 / 3$ drivers (33.3\%) in type $\mathrm{D}$ were male. In total, there were 6-over-65-yearsold drivers: no one in type A; 1 driver $(16.7 \%)$ in type $\mathrm{D}, 2$ drivers $(33.3 \%)$ in type $\mathrm{C}$, and $3 / 6$ drivers $(50 \%)$ in type $\mathrm{B}$.

\subsection{Descriptive Data}

Figure 4 showed profiles of sample means and 95-percent confidence interval $(95 \% \mathrm{CI})$ of population means of the lateral gap from SV to VRU and ratio of SV speed to initial speed for each type of driver. In increasing order, the $95 \% \mathrm{CI}$ of lateral passing gap means of type D, type C, type B, type A drivers were $[0.921,1.03] \mathrm{m},[1.08,1.15] \mathrm{m},[1.37,1.45] \mathrm{m}$, $[1.92,2.17] \mathrm{m}$, respectively. The drivers in type $B$ and type $C$ chose to drive closely to the initial speed. Their $95 \% \mathrm{CI}$ of the ratio of minimum vehicle speed to initial speed were: $[0.752,0.790]$ and $[0.873,0.889]$, respectively. Their $95 \% \mathrm{CI}$ of the ratio of passing speed to initial speed means were: [0.875, 0.935] and [1.05, 1.11], respectively. On the one hand, drivers in type D preferred speeding from the beginning. $95 \% \mathrm{CI}$ of their ratio of minimum speed and passing speed to initial speed of road were: [0.984, 0.999] and $[1.29,1.39]$, respectively. On the other hand, type A drivers always reduced speed. Their $95 \%$ CI of the ratio of minimum speed to initial speed was [0.592, 0.652]. They passed the VRU at the ratio of passing speed to initial speed mean of $95 \%$ CI [0.702, 0.786]. Table 2 provides descriptive statistics of LPG, RMS that outline the data of each group. Figures 5-8 show the box plots related to LPG and RMS for all types in different conditions of lane width, SV's initial speed, VRU type, and location, respectively. Overall, the mean profiles were different for each group of drivers. 
a)

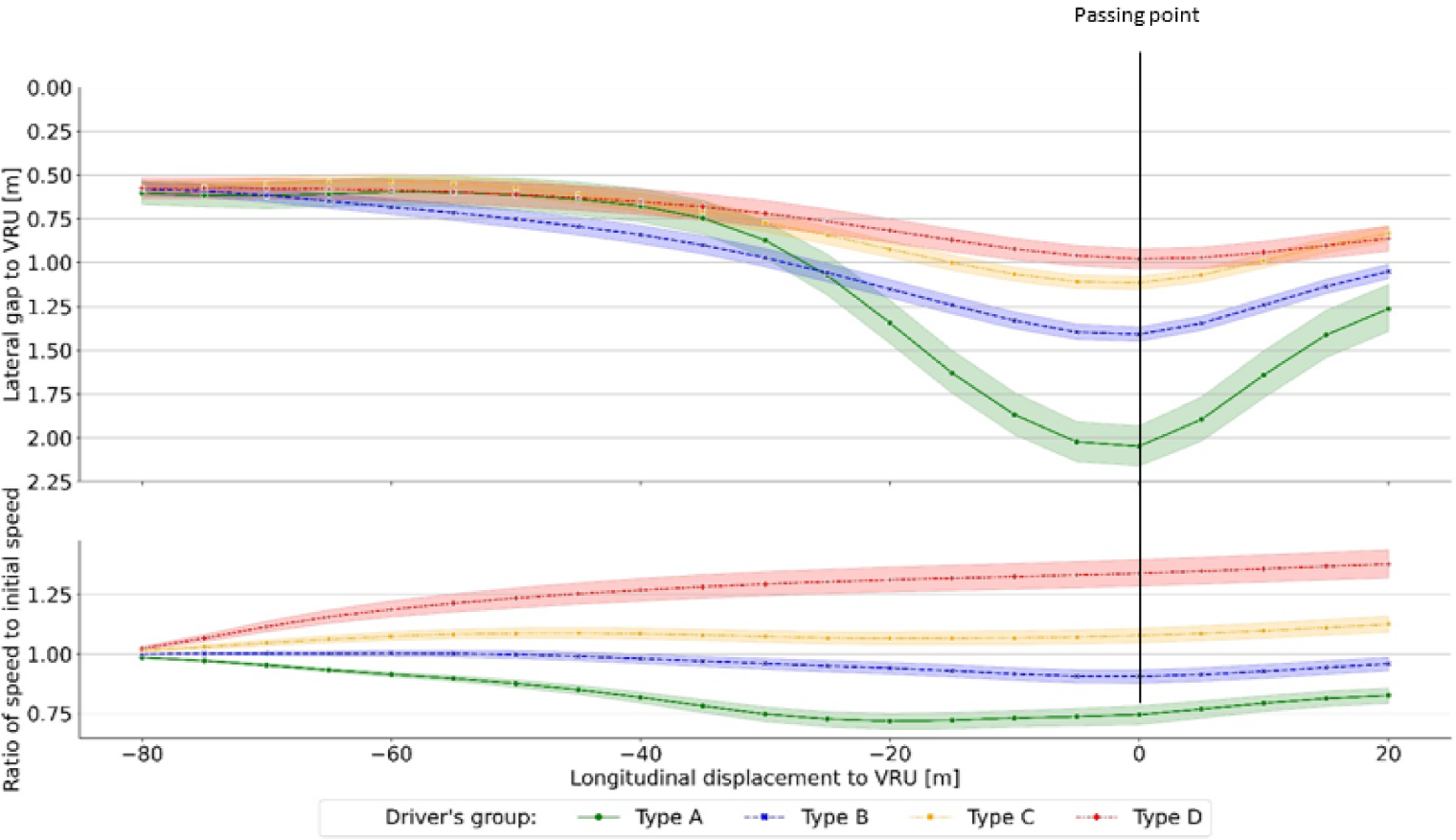

Figure 4. Profiles of sample means (lines) and 95\% confidence interval (95\% CI) of population means (shade) of the lateral gap from SV to VRU (a) and the ratio of SV velocity to initial speed (b) over longitudinal displacement for each group of drivers.

Table 2. Descriptive statistics (mean, standard deviation) for each driver group.

\begin{tabular}{ccccc}
\hline Metrics & Type A & Type B & Type C & Type D \\
\hline LPG $[\mathrm{m}]$ & $2.05(0.57)$ & $1.41(0.38)$ & $1.12(0.32)$ & $0.98(0.34)$ \\
\hline RMS & $0.62(0.13)$ & $0.77(0.17)$ & $0.89(0.11)$ & $0.99(0.04)$ \\
\hline
\end{tabular}

The LPG indicates the safety gap perception of drivers when they overtaking VRU. The upper panel of Figure 4 shows that the average LPG profiles for all four types of drivers were bigger than the gap at the beginning of manual mode. So, drivers, normally do not ignore the existence of VRU even when they were in the walking/cycling lane. Despite type B's gap profile gradually increased from the beginning, the gap profiles of others started increasing when longitudinal displacement from SV to VRU was about $40 \mathrm{~m}$.

The lower panel of Figure 4 shows, on average, how the drivers regulate the vehicle speed in comparison to the initial speed. The graphs reveal the speeding tendency of type D drivers. They accelerated from the beginning of the manual mode. The type A drivers were in the opposition, always reduced the speed. While type B and type C drivers maintained their speed. The ratio of SV speed to initial speed indicates overtaking strategy of drivers. From those profiles, only the type A drivers chose the accelerative overtaking strategy. 


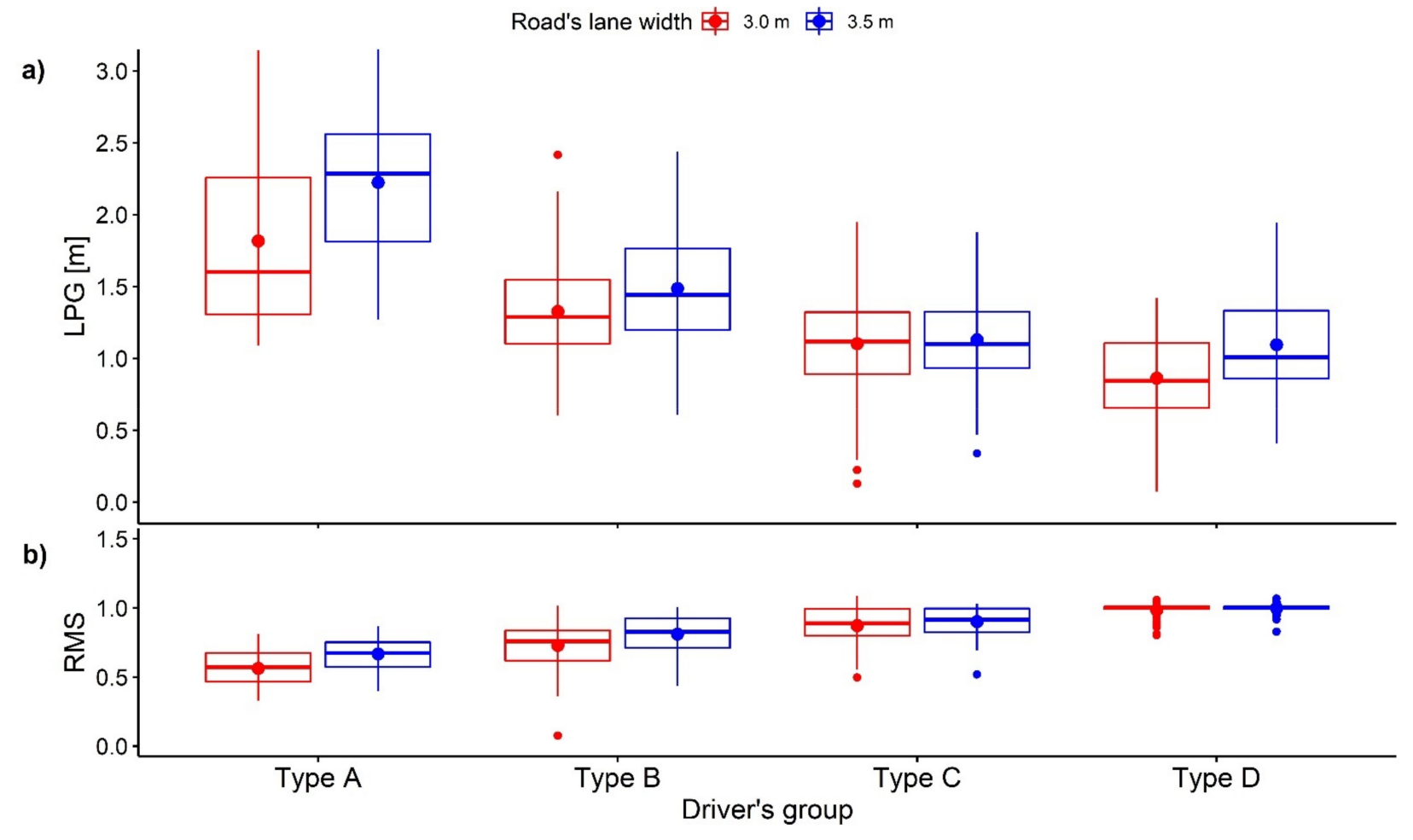

Figure 5. Box plots of the minimum lateral gap while passing VRU (a) and the ratio of SV's minimum velocity to initial speed while approaching VRU (b), grouped by road's lane width between driver's groups.

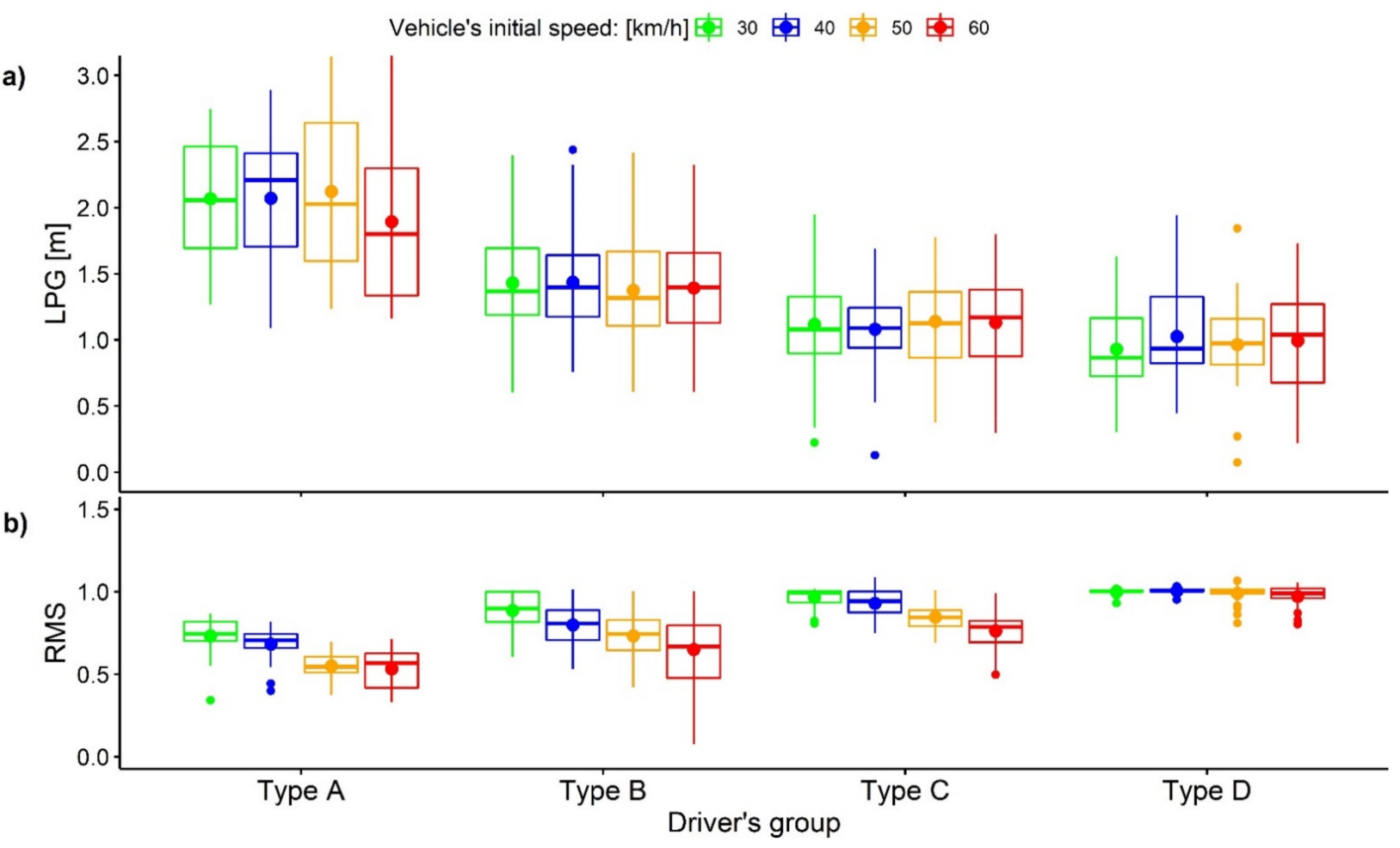

Figure 6. Box plots of the minimum lateral gap while passing VRU (a) and the ratio of SV's minimum velocity to initial speed while approaching VRU (b), grouped by initial speed between driver's groups. 


\section{VRU's type Adult Cyclist}

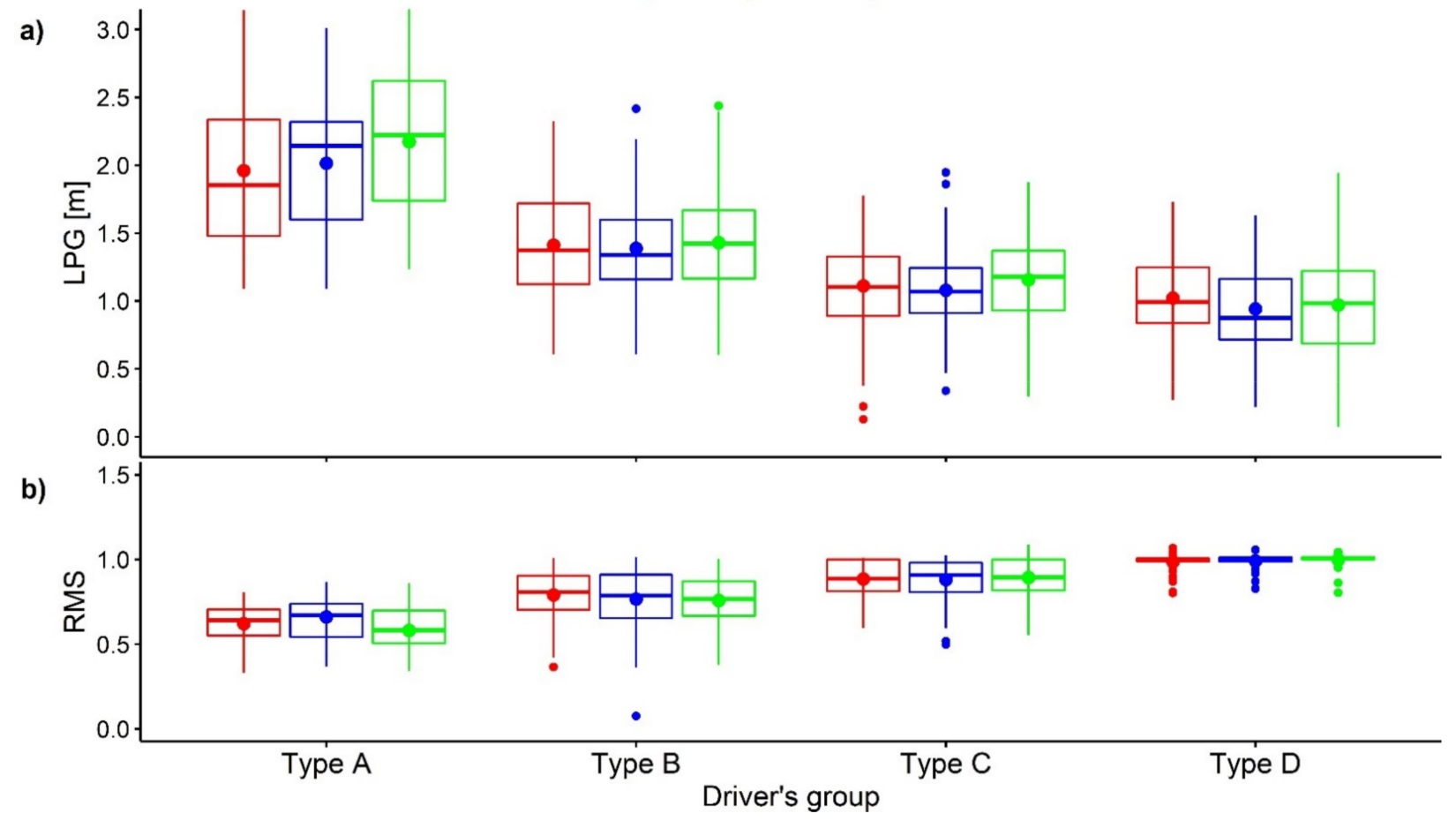

Figure 7. Box plot of the minimum lateral gap while passing VRU (a) and the ratio of SV's minimum velocity to initial speed while approaching VRU (b), grouped by VRU's type between driver's groups.

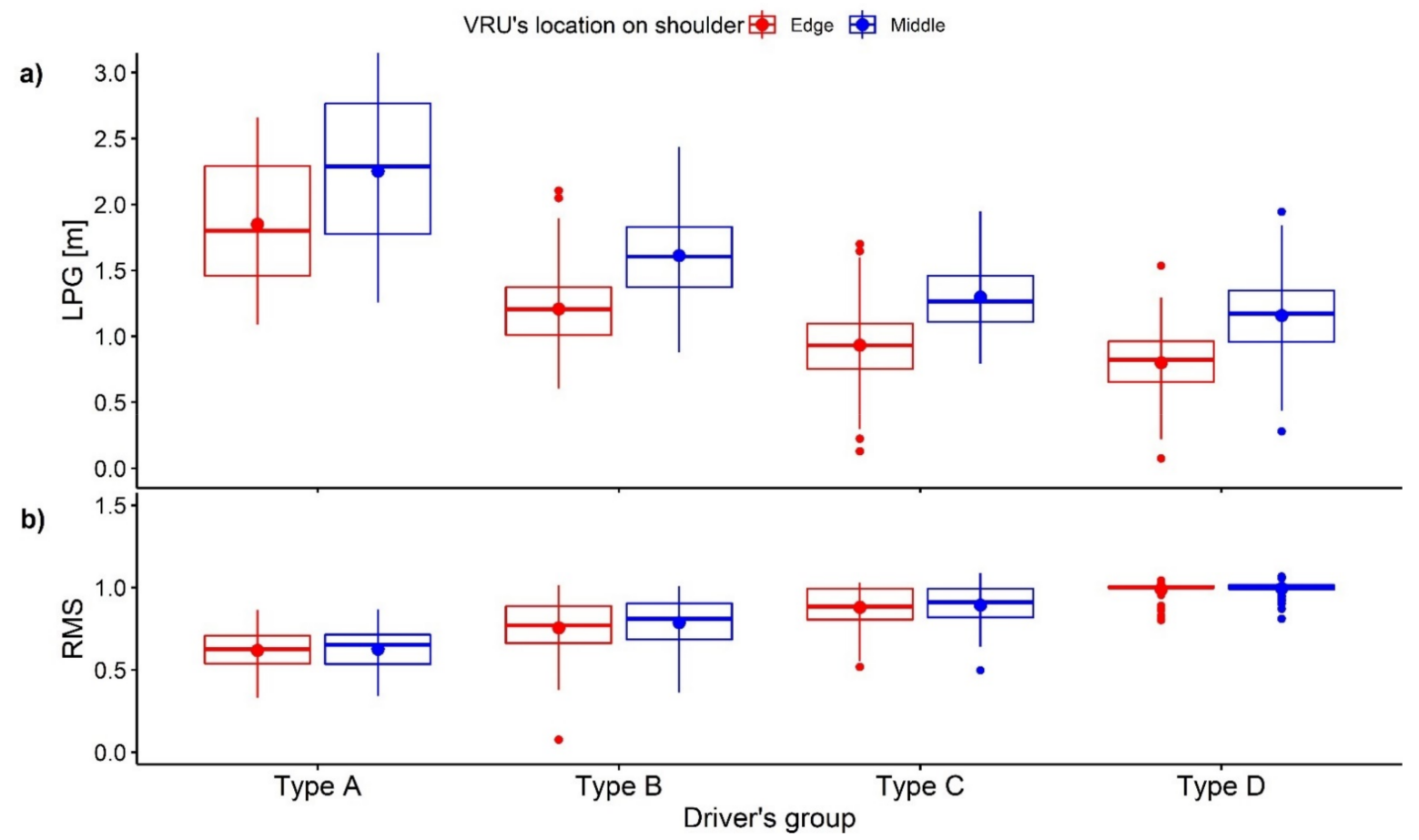

Figure 8. Box plots of the minimum lateral gap while passing VRU (a) and the ratio of SV's minimum velocity to initial speed while approaching VRU (b), grouped by VRU's location between driver's groups. 


\subsection{Effects of Interaction between Factors on Driver Behavior}

Table 3 suggested only the interaction between lane width and car's initial speed was significant on LPG of drivers in Type A and Type B $(p<0.001$ and $p<0.05$, respectively). The drivers in Type $\mathrm{D}$ were influenced by the interaction between type and location of VRU $(p<0.05)$. However, no interaction was significant to drivers in Type $C(p>0.05)$.

Table 3. Results of significance tests for interactions between car's initial speed, road's lane width, VRU's type, VRU's location on LPG and RMS for each driver's group.

\begin{tabular}{|c|c|c|c|c|c|c|c|c|}
\hline \multirow{2}{*}{$\begin{array}{l}\text { Fixed } \\
\text { Effects }\end{array}$} & \multicolumn{4}{|c|}{ LPG } & \multicolumn{4}{|c|}{ RMS } \\
\hline & Type A & Type B & Type C & Type D & Type A & Type B & Type C & Type D \\
\hline LW:Is:T:L & - & - & - & - & - & - & - & - \\
\hline LW:Is:T & - & - & - & - & $* *$ & - & - & - \\
\hline LW:T:L & - & - & - & - & - & - & - & - \\
\hline LW:Is:L & - & - & - & - & - & * & - & - \\
\hline Is:T:L & - & - & - & - & - & - & - & - \\
\hline LW:Is & $* * *$ & * & - & - & $* * *$ & - & $* * *$ & - \\
\hline $\mathrm{T}: \mathrm{L}$ & - & - & - & * & - & * & - & - \\
\hline LW:T & - & - & - & - & - & - & - & - \\
\hline Is:L & - & - & - & - & - & - & - & - \\
\hline LW:L & - & - & - & - & - & - & - & - \\
\hline Is:T & - & - & - & - & $* *$ & - & - & - \\
\hline
\end{tabular}

For RMS, three interactions were significant to drivers in Type A: the interaction between lane width, initial speed, and VRU type $(p<0.01)$, the interaction between lane width and initial speed $(p<0.001)$, the interaction between initial speed and VRU type $(p<0.01)$. Type B was influenced by the interaction between lane width, initial speed, and VRU location $(p<0.05)$, the interaction between VRU type and location $(p<0.05)$. The interaction between the lane width of the road and the initial speed of the vehicle has a statistically significant impact on the RMS of Type C $(p<0.001)$. All interactions were dropped due to no significance to Type $\mathrm{D}(p>0.05)$.

\subsection{Effects of Different Factors on Driver Behavior}

\subsubsection{Lane Width}

Each driver had 48 samples in total and 24 samples/types of lane width. So that, there were $48,168,144,72$ samples/types of lane width for type A, type B, type C, and type D, respectively.

The Repeated Measures ANOVA tests on LPG revealed a significant effect of lane width for type A, type B and type D drivers, $\mathrm{F}(1,34)=30.411, p<0.0001, \eta^{2}{ }_{\mathrm{G}}=0.092$; $\mathrm{F}(1,137)=31.48, p<0.0001, \eta^{2} \mathrm{G}=0.044 ; \mathrm{F}(1,71)=31.78, p<0.0001, \eta^{2}{ }_{\mathrm{G}}=0.116$, respectively. TukeyHSD tests showed statistically significant difference between LPG on $3.0 \mathrm{~m}$ lane width and $3.5 \mathrm{~m}$ lane width, with estimate values were $-0.408 \mathrm{~m}$ (standard error SE $=0.12$ ), $-0.159 \mathrm{~m}(\mathrm{SE}=0.043),-0.233 \mathrm{~m}(\mathrm{SE}=0.054)$, respectively (Table 4$)$. The tests with type $\mathrm{C}$ drivers disclosed no statistically significant effect of lane width $\mathrm{F}(1,131)=0.819, p>0.05$. 
Table 4. TukeyHSD tests' result for lane width effect.

\begin{tabular}{ccccc}
\hline & Type A & Type B & Type C & Type D \\
\hline LPG & $* *$ & $* * *$ & - & $* * * *$ \\
\hline RMS & $* * *$ & $* * * *$ & $*$ & - \\
\hline Significance sign: $\left.(-) p>0.05\left(^{*}\right) ; p<0.05\left(^{* *}\right) ; p<0.01{ }^{* * *}\right) ; p<0.001 ;\left({ }^{* * * *}\right) p<0.0001$.
\end{tabular}

In this study, two types of roads were analyzed: 3.5-m-lane-width road with a centerline and 3.0-m-lane-width road without a centerline. The higher the lane width, the larger the passing gap is allowed. This is consistent with the rural-road studies $[4,16,20,25]$. It is worth notice that type $C$ and type D drivers overtook VRU without a significant difference in LPG for the two roads.

Besides, the Repeated Measures ANOVA tests on RMS showed a statistically significant effect on all types of drivers: $F(1,34)=11.96, p=0.001, \eta^{2}{ }_{G}=0.099$ (type A drivers), $\mathrm{F}(1,137)=45.49, p<0.0001, \eta_{\mathrm{G}}^{2}=0.075$ (type $\mathrm{B}$ drivers), $\mathrm{F}(1,131)=10.69$, $p=0.001, \eta^{2}{ }_{G}=0.016$ (type $\mathrm{C}$ drivers), $\mathrm{F}(1,71)=4.01, p<0.05, \eta^{2}{ }_{\mathrm{G}}=0.022$ (type $\mathrm{D}$ drivers) TukeyHSD tests showed statistically significant difference between RMS on $3.0 \mathrm{~m}$ lane width and $3.5 \mathrm{~m}$ lane width, with estimate values were $-0.104(\mathrm{SE}=0.028),-0.081$ $(\mathrm{SE}=0.019),-0.028(\mathrm{SE}=0.013),-0.013(\mathrm{SE}=0.007)$, respectively.

From the analysis, it is confirmed that lane width had a significant effect on vehicle speed. Type A, type B, type $C$ drivers always selected higher speeds on wide roads. However, there were no statistically significant effects of lane width on the lateral passing gap of type $C$ drivers and the speed of type $D$ drivers. These results can be explained by the perception of those drivers. Type $C$ drivers always keep a constant gap to VRU. While type D drivers' speeding behavior was not affected by travel space of road.

\subsubsection{Initial Speed of Vehicle}

Each driver had 48 samples in total and 12 samples/types of the initial speed. So that, there were $24,84,72,36$ samples/types of initial speed for type A, type B, type C, and type $\mathrm{D}$, respectively.

The Repeated Measures ANOVA tests on LPG did not reveal a significant effect of vehicle's initial speed for all drivers' types, $\mathrm{F}(3,39)=0.161, p>0.05$ (type $\mathrm{A}) ; \mathrm{F}(3,177)=1.105$, $p>0.05$ (type $\mathrm{B}) ; \mathrm{F}(3,141)=1.88, p>0.05$ (type $\mathrm{C}) ; \mathrm{F}(3,105)=1.03, p>0.05$ (type $\mathrm{D})$, respectively.

The analysis of the influence of initial speed on LPG showed new information compared to previous research $[2,20]$ : although each group had its own LPG range, there was no statistically significant effect of different initial speeds in each group behavior. This non-significant result in driver's LPG's perception across speed conditions is instructive for two reasons. First, it shows that the vehicle's initial speed did not have any effect on the experimentee's perception of the lateral gap. Second, it suggests that the results of this study can be compared to other studies which researched on overtaking behavior on a straight road with different speed.

On the contrary, the Repeated Measures ANOVA tests on RMS showed a statistically effect of initial speed for all type $A$, type $B$, type $C$ and type $D$ of drivers: $F(1.03,40.34)=13.45$, $\mathrm{GGe}=0.825, p<0.0001, \eta^{2}{ }_{\mathrm{G}}=0.495 ; \mathrm{F}(2.46,145.02)=52.82, \mathrm{GGe}=0.785, p<0.001$, $\eta^{2}{ }_{\mathrm{G}}=0.266 ; \mathrm{F}(2.07,97.06)=58.68, \mathrm{GGe}=0.688, p<0.001, \eta^{2}{ }_{\mathrm{G}}=0.451 ; \mathrm{F}(1.93,67.5)=5.19$, $\mathrm{GGe}=0.643, p<0.01, \eta^{2}{ }_{\mathrm{G}}=0.087$, respectively. In those tests, Mauchly's Test of Sphericity indicated that the assumption of sphericity had been violated, and therefore, a GreenhouseGeisser correction was used. TukeyHSD tests disclosed statistically significant different between most pairs of initial speed for all types of drivers (Table 5). 
Table 5. TukeyHSD test results for the initial speed effect.

\begin{tabular}{cccccc}
\hline & & Type A & Type B & Type C & Type D \\
\hline \multirow{2}{*}{ LPG } & all & - & - & - & - \\
\hline & $30-40$ & - & $* *$ & $*$ & - \\
\cline { 2 - 6 } & $30-50$ & $* * * *$ & $* * * * * *$ & $* * * *$ & $*$ \\
\cline { 2 - 6 } RMS & $30-60$ & $* * * *$ & $* * *$ & $* * *$ & - \\
\cline { 2 - 5 } & $40-50$ & $* * *$ & $*$ & $* * * *$ & $*$ \\
\cline { 2 - 5 } & $40-60$ & $* * * * * * *$ & $*$ & $*$ \\
\hline
\end{tabular}

For all types, the initial speed had a statistically significant effect on how the drivers regulated their vehicle speed. This finding can be explained as the perception of collision to VRU is different across velocities: the higher the speed, the smaller the time-to-collision for drivers to consider the situation and decide to take a maneuver. Moreover, for type A drivers, there was no difference in overtaking strategies between the initial speed of $30-40 \mathrm{~km} / \mathrm{h}$. Type D drivers' strategy was different only in the case of an initial speed of $60 \mathrm{~km} / \mathrm{h}$.

\subsubsection{Types of Vulnerable Road Users}

Each driver had 48 samples in total and 16 samples/types of VRU. So that, there were $32,112,96,48$ samples/types of VRU for type A, type B, type C, and type D, respectively.

The Repeated Measures ANOVA tests on LPG only disclosed the statistically effect of VRU types for type A drivers: $\mathrm{F}(2,46)=8.95, p<0.001, \eta^{2}{ }_{\mathrm{G}}=0.018$. But pairwise comparisons did not show any statistically significant for pairs of adult, child and cyclist (Table 6). Additionally, the effect of VRU types on LPG was not statistically significant for type $\mathrm{B}$, type $\mathrm{C}$, type $\mathrm{D}$ drivers: $\mathrm{F}(2,198)=1.31, p>0.05 ; \mathrm{F}(2,174)=3.01, p=0.052$; $\mathrm{F}(2,94)=1.185, p>0.05$, respectively.

Table 6. TukeyHSD tests' result for VRU type effect.

\begin{tabular}{ccccc}
\hline & Type A & Type B & Type C & Type D \\
\hline LPG & - & - & - & - \\
\hline RMS & - & - & - & - \\
\hline
\end{tabular}

Significance sign: (-) $p>0.05$.

The Repeated Measures ANOVA tests on RMS revealed statistically significant effect of VRU types on type A and type B drivers: $\mathrm{F}(1.58,36.43)=5.79, \mathrm{GGe}=0.751, p=0.01$; $\mathrm{F}(2,198)=3.92, p=0.021$, respectively. However, TukeyHSD tests did not show any statistically significant effects in pairs. For type A, Mauchly's Test of Sphericity indicated that the assumption of sphericity had been violated, and therefore, a Greenhouse-Geisser correction was used. The effect of VRU types on RMS for type $C$ and type D drivers were also not statistically significant: $\mathrm{F}(2,174)=0.822, p>0.05 ; \mathrm{F}(2,94)=1.57, p>0.05$, respectively.

The analyses showed that VRU type does not have a statistically significant effect on drivers. Interestingly, all drivers had the same perception for every kind of VRU type despite the fact they were in different shapes and speeds. These results suggested other characteristics of VRU should be considered, such as direction and trajectory.

\subsubsection{Location of Vulnerable Road Users on Shoulder}

Each driver had 48 samples in total and 24 samples/types of lane width. So that, there were $48,168,144,172$ samples/types of lane width for type A, type B, type C, and type D, respectively. 
The Repeated Measures ANOVA tests on LPG showed a statistically effect of VRU location for all type A, type B, type $C$ and type D drivers: $F(1,37)=91.03, p<0.0001$, $\eta_{\mathrm{G}}^{2}=0.124 ; \mathrm{F}(1,149)=315.15, p<0.0001, \eta_{\mathrm{G}}^{2}=0.291 ; \mathrm{F}(1,131)=202.86, p<0.0001$, $\eta^{2}{ }_{G}=0.451 ; F(1,71)=70.48, p<0.0001, \eta^{2}{ }_{G}=0.273$, respectively. TukeyHSD tests disclosed statistically significant different between all pairs of initial speed for all drivers' types (Table 7).

Table 7. TukeyHSD test results for the VRU location effect.

\begin{tabular}{ccccc}
\hline & Type A & Type B & Type C & Type D \\
\hline LPG & $* *$ & $* * * *$ & $* * * *$ & $* * * *$ \\
\hline RMS & - & - & - & - \\
\hline Significance sign: $(-) p>0.05 ;\left(^{*}\right) p<0.05 ;\left(^{* *}\right) p<0.01 ;(* * *) p<0.001 ;(* * *) p<0.0001$.
\end{tabular}

The Repeated Measures ANOVA tests on RMS also disclosed the statistically effect of VRU location for type $B$ and type $C$ drivers: $F(1,149)=10.19, p<0.01, \eta^{2}{ }_{G}=0.009$; $\mathrm{F}(1,131)=4.56, p=0.035, \eta^{2}{ }_{\mathrm{G}}=0.004$, respectively. But pairwise comparisons did not show any statistically significant for pairs of adult, child and cyclist. Additionally, the effect of VRU location on LPG was not statistically significant for type A, type D drivers: $\mathrm{F}(1,37)=0.79, p>0.05 ; \mathrm{F}(1,71)=1.44, p>0.05$, respectively.

The lateral passing gap to VRU was clearly higher when VRU moved in the middle of the walking lane than when VRU was on the edge near the vehicle lane. This finding is consistent with other researches [11,17,20]. In line with [17], the location of VRU was found to have a statistically significant effect on the passing speed between groups. In each group, the effect on passing speed was not statistically significant. The type A and type D drivers kept their speeding tendency constantly across VRU locations in two opposite directions: always slows down and always accelerates.

\section{Discussion}

This study investigated the diverse driving style while drivers overtake a vulnerable road user. The driving styles include the minimum lateral gap while passing VRU and the ratio of the vehicle's minimum speed while approaching VRU to initial speed.

\subsection{Driver Behavior}

Overall, the average LPG of a major part of drivers (16/18 88.9\%) in an urban area in the experiment was less than $1.5 \mathrm{~m}$ rule for the rural road. So that, safety systems should have a different threshold for overtaking in an urban area. It is worth notice that the accepted LPG of type A was identical and much larger than others. It seemed that they had changed lanes to avoid the potential collision with VRU.

The results also uncovered that all types of drivers reduced speed when approaching the VRU, except type D. According to strategy definition [2], most drivers (15/18 drivers) chose accelerative overtaking strategy. It is aligned with the finding of Rasch et al. [11]. However, the type D drivers' strategy was flying overtaking, and their average speed were always bigger than the initial speed.

More details, type $B$ and type $C$ drivers, who were considered as competent groups have various differences in driving style. The average accepted LPG of type B was larger than type C's value. Type B's LPG perception was influenced by the interaction between lane width and initial speed, main effects of lane width, VRU location, while type C's LPG was only affected by lane width of the further road. Moreover, drivers in type B slightly decelerated in the approaching phase, but drivers in type $C$ slightly speeded up before making an overtaking decision. However, their tendencies in regulating the speed had been impacted by the same main factors: the lane width and initial speed while VRU characteristics did not have a statistical effect. 
Furthermore, the driving styles of type A (conservative style) and type D (aggressive style) drivers are worth noticing. On the one hand, type A drivers always slowed down before making a decision which may cause trouble to traffic flow and kept large LPG to VRU. Lateral gap perception of type A drivers was statistically significantly influenced by lane width of the road, VRU location on the shoulder, and the interaction between lane width and initial speed. Although they always decreased speed, various interactions, and main effects of lane width, initial speed, VRU type still have a significant effect on RMS. On the other hand, type $\mathrm{D}$ drivers posed a high risk of collision due to their speeding tendency and small LPG to VRU while overtaking. Their RMS was influenced only by the vehicle's initial speed. Their LPG was affected by the road's lane width and VRU location. In line with [15], the difference between types can be seen far from the passing point, but it is best explained when SUV was at the distance from 40 to $20 \mathrm{~m}$ to VRU's passing point. The difference of type $A$ and type $D$ in speed can be recognized even at the distance of $60 \mathrm{~m}$ before the passing point.

Due to various driving styles, there is a need for a personalized assisting system that will enhance driver acceptance with the system's warning and/or response. These pieces of information help design safety systems to warn drivers and intervene in VRU avoidance with regards to driving style, road, and VRU characteristics.

\subsection{Implications for Safety Systems and Automated Driving}

Safety systems that provide VRU overtaking maneuver assistance may raise a warning and / or avoid a potential collision automatically. Proposed actions for avoidance can be braking or steering without the existence of an oncoming vehicle [17] based on risk indices, such as TTC, PRE, driver's comfort zone ... [ [2,13] These systems may be useless without acceptance from drivers. This acceptance is complicated because each person at different times is not the same. Our study suggests several driver's groups who really need this kind of assistance (group A), some only need the correction for bad situations (group D) and those may need the safety systems. Further research to find the suitable response and thresholds for warning, intervention for each group will enhance the practicable of such systems.

In automated driving, path planning with regards to perception from driver's groups may lead to suitable choices in overtaking maneuvers. Using the thresholds of lateral distance to VRU and overtaking strategy, overtaking speed in the desired range of drivers, the systems can develop a reference path with regards to safety and driver's satisfaction. Moreover, knowledge about the effects of various factors such as road (lane width), vehicle speed, a pedestrian (type, location on shoulder) will benefit the setup, simplify the development of such a system.

\subsection{Limitations}

Drivers were told to perform driving as normally as possible, without any restriction of speed and space to the pedestrian. This might not be the case under certain situations (limit in sight condition, approaching oncoming vehicle ... ) which have a great impact on the driver's response [17]. The threat of collision may lead to the case of aborting the overtaking maneuver [17], which was not analyzed.

Another limitation is that the data was obtained from Japanese people in fixed conditions in a driving simulator. It is argued that drivers from other countries in which there is a rule about the lateral distance may have different attitudes to the VRU. Therefore, the detailed information about LPG, RMS should be verified using naturalistic driving and/or field test data in other countries.

At this stage of the research, driver's characteristic factors still have not been investigated due to some attributes, such as gender and age but were reported to have no significant effect on LPG [12]. Young people did not include in the participant list, which aims to represent Japanese aging drivers who have solid experience in driving. Inexperienced drivers, whose behavior is difficult to predict, and were not covered in this study. 
Other driver states such as inattention, drunk, dizzy ... are also not included. The variation of driver states and driver characteristics may influence driver behavior. These convey the directions for research in the near future.

\section{Conclusions}

In this study, we scrutinized driver avoidance behavior for vulnerable road users moving along the urban-straight road. The results were interesting in the sense that drivers can choose different approaching and overtaking strategies. However, the data suggested that each driver stuck to a unique strategy in the perception of the lateral gap to VRU and minimum speed. Otherwise, the analysis showed that road and VRU characteristics have different effects on those driving styles.

The findings of four types of drivers with two-worth-notice groups (type $\mathrm{A}$ and type $\mathrm{D}$ drivers) raised the need to correct this abnormal behavior in different driving conditions. Each type of driver perceives the surrounding environment, roads, and other road users differently. This finding is useful in designing ADAS systems to improve mutual understanding and mutual control.

Author Contributions: Conceptualization, all authors; methodology, M.D.V.; software, M.D.V. and S.N.; validation, M.D.V., S.N., H.A., and Q.H.N.V.; formal analysis, M.D.V., S.N., and H.A.; investigation, M.D.V., H.A., and Q.H.N.V.; resources, H.A., T.S., S.N., Q.H.N.V., S.I. and A.H.; data curation, M.D.V. and S.N.; writing-original draft preparation, M.D.V.; writing-review and editing, all authors; visualization, M.D.V. and S.N.; supervision, H.A., T.S., and Q.H.N.V. All authors have read and agreed to the published version of the manuscript.

Funding: This research received no external funding.

Institutional Review Board Statement: The study was conducted according to the guidelines of the Declaration of Helsinki, and approved by the Ethics Committee of the Institute of Innovation for Future Society, Nagoya University.

Informed Consent Statement: Informed consent was obtained from all subjects involved in the study.

Data Availability Statement: The data presented in this study are available on request from the corresponding author. The data are not publicly available due to privacy restrictions.

Acknowledgments: In this section, you can acknowledge any support given which is not covered by the author's contribution or funding sections. This may include administrative and technical support, or donations in kind (e.g., materials used for experiments).

Conflicts of Interest: The authors declare no conflict of interest.

\section{References}

1. Amini, R.E.; Katrakazas, C.; Antoniou, C. Negotiation and decision-making for a pedestrian roadway crossing: A literature review. Sustainability 2019, 11, 6713. [CrossRef]

2. Dozza, M.; Schindler, R.; Bianchi-Piccinini, G.; Karlsson, J. How do drivers overtake cyclists? Accid. Anal. Prev. 2016, 88, 29-36. [CrossRef] [PubMed]

3. Borowsky, A.; Shinar, D.; Oron-Gilad, T. Age, skill, and hazard perception in driving. Accid. Anal. Prev. 2010, 42, 1240-1249. [CrossRef] [PubMed]

4. Jansen, R.; Lotan, T.; Winkelbauer, M.; Bärgman, J.; Kovaceva, J.; Donabauer, M.; Pommer, A.; Musicant, O.; Harel, A.; Wesseling, S.; et al. Interactions with Vulnerable Road Users. UDRIVE Deliverable 44.1. EU FP7 Project UDRIVE Consortium; European Commission: Brussels, Belgium, 2017. [CrossRef]

5. Nagiri, S.; Aoki, H.; Vu, M.D.; Nguyen Van, Q.H.; Itou, S.; Hattori, A. Experimental Study on Driving Behavior of General Driver when Passing the Pedestrian's Side. Trans. Soc. Automot. Eng. Jpn. 2021, 52, 480-485. [CrossRef]

6. Boda, C.N.; Dozza, M.; Bohman, K.; Thalya, P.; Larsson, A.; Lubbe, N. Modelling how drivers respond to a bicyclist crossing their path at an intersection: How do test track and driving simulator compare? Accid. Anal. Prev. 2018, 111, 238-250. [CrossRef]

7. Dozza, M.; Boda, C.N.; Jaber, L.; Thalya, P.; Lubbe, N. How do drivers negotiate intersections with pedestrians? The importance of pedestrian time-to-arrival and visibility. Accid. Anal. Prev. 2020, 141, 105524. [CrossRef] [PubMed]

8. Ezawa, K.; Raksincharoensak, P.; Akagi, Y.; Maeda, K.; Kojima, T. Study on autonomous braking control system based on motion prediction considering overtaking motion of cyclists. Trans. JSME 2018, 84, 1-12. [CrossRef] 
9. Tagawa, T.; Sato, K.; Shino, M. Collision risk with visible pedestrian caused by driver error while driving on non-intersection road. Trans. Soc. Automot. Eng. Jpn. 2016, 47, 543-548.

10. Matson, T.; Forbes, T. Overtaking and passing requirements as determined from a moving vehicle. In Proceedings of the Highway Research Board, Washington, DC, USA, 28 November-2 December 1938; pp. 100-112. Available online: https: // trid.trb.org/view/120830 (accessed on 1 June 2021).

11. Rasch, A.; Boda, C.N.; Thalya, P.; Aderum, T.; Knauss, A.; Dozza, M. How do oncoming traffic and cyclist lane position influence cyclist overtaking by drivers? Accid. Anal. Prev. 2020, 142, 105569. [CrossRef]

12. Kovaceva, J.; Nero, G.; Bärgman, J.; Dozza, M. Drivers overtaking cyclists in the real-world: Evidence from a naturalistic driving study. Saf. Sci. 2019, 119, 199-206. [CrossRef]

13. Aoki, H.; Yasuda, H.; Fukui, T. A study on the longitudinal risk estimate. Trans. Soc. Automot. Eng. Jpn. 2011, 42, 619-623. [CrossRef]

14. Bianchi Piccinini, G.F.; Moretto, C.; Zhou, H.; Itoh, M. Influence of oncoming traffic on drivers' overtaking of cyclists. Transp. Res. Part F Traffic Psychol. Behav. 2018, 59, 378-388. [CrossRef]

15. Farah, H.; Bianchi Piccinini, G.F.; Itoh, M.; Dozza, M. Modelling overtaking strategy and lateral distance in car-to-cyclist overtaking on rural roads: A driving simulator experiment. Transp. Res. Part F Traffic Psychol. Behav. 2019, 63, 226-239. [CrossRef]

16. Feng, F.; Bao, S.; Hampshire, R.C.; Delp, M. Drivers overtaking bicyclists-An examination using naturalistic driving data. Accid. Anal. Prev. 2018, 115, 98-109. [CrossRef] [PubMed]

17. Rasch, A.; Panero, G.; Boda, C.N.; Dozza, M. How do drivers overtake pedestrians? Evidence from field test and naturalistic driving data. Accid. Anal. Prev. 2020, 139, 105494. [CrossRef] [PubMed]

18. Haraguchi, T.; Kaneko, T.; Kageyama, I.; Kuriyagawa, Y.; Kobayashi, M. Study of Tilting Type Personal Mobility Vehicle by the Immersive Driving Simulator with Five Large Screens. Trans. Soc. Automot. Eng. Jpn. 2017, 48, 693-698. [CrossRef]

19. Gemba, M.; Haraguchi, T.; Aoki, H.; Tanaka, T. Study of the Human-vehicle System by a Driving Simulator with Stereoscopic Vision of Five Large Screens (First Report). Trans. Soc. Automot. Eng. Jpn. 2016, 47, 783-788.

20. Bates, D.; Mächler, M.; Bolker, B.M.; Walker, S.C. Fitting linear mixed-effects models using lme4. J. Stat. Softw. 2015, 67, 1-48. [CrossRef]

21. Kuznetsova, A.; Brockhoff, P.B.; Christensen, R.H.B. lmerTest package: Tests in linear mixed effects models. J. Stat. Softw. 2017, 82, 1-26. [CrossRef]

22. Kassambara, A. Rstatix: Pipe-Friendly Framework for Basic Statistical Tests. 2021. Available online: https://cran.r-project.org/ web / packages/rstatix/index.html (accessed on 2 February 2021).

23. Russell, V.L.; Paul, B.; Maxime, H.; Jonathon, L.; Hannes, R.; Henrik, S. Emmeans: Estimated Marginal Means, Aka Least-Squares Means. 2021. Available online: https:/ / cran.r-project.org/web/packages/emmeans/index.html (accessed on 2 February 2021).

24. Rubie, E.; Haworth, N.; Twisk, D.; Yamamoto, N. Influences on lateral passing distance when motor vehicles overtake bicycles: A systematic literature review. Transp. Rev. 2020, 40, 754-773. [CrossRef]

25. Mecheri, S.; Rosey, F.; Lobjois, R. Manipulating constraints on driver-cyclist interactions in a fixed travel space: Effects of road configuration on drivers' overtaking behavior. Saf. Sci. 2020, 123, 104570. [CrossRef]

\section{Short Biography of Authors}

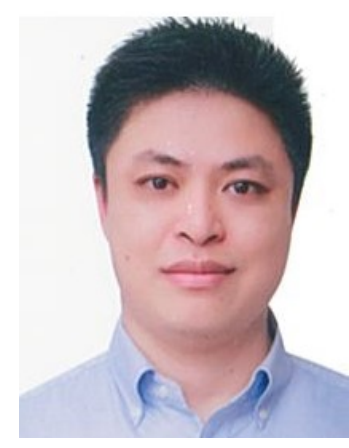

Manh Dung $\mathbf{V u}$ received the B.E. and M.E. degrees in Automotive Engineering from Le Quy Don Technical University, Vietnam in 2010 and 2016, respectively. $\mathrm{He}$ is currently working towards the Doctor's degree with the Department of Mechanical Systems Engineering, Nagoya University, Japan. His research interests are in the areas of Human Factors Engineering and its applications to the analysis and modeling of human behavior towards the personalization for advanced driver assistance system and automated driving.

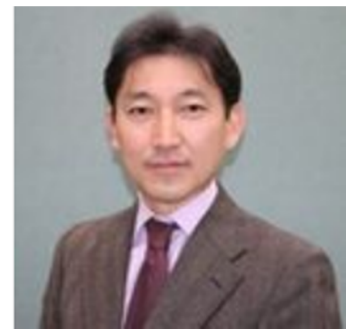

Hirofumi Aoki received the B.S. degree from Waseda University in 1996, and the M.S., Ph.D. degrees from Tokyo Institute of Technology, Japan in 1999, 2002, respectively. From 2004 till 2007, he had been in the Man-Vehicle Laboratory at MIT as a postdoctoral associate as well as postdoctoral fellow of the National Space Biomedical Research Institute. Then, he worked with Toyota Motor Corporation, where he did R\&D of the advanced driver assistance systems. In 2014, he became a professor at the Institutes of Innovation for Future Society, Nagoya University. He received several scientific awards including the best scientific paper award in the ITS World Congress 2013 and the best paper award in IEEE-EmergiTech 2016. Dr. Aoki is a Certified Professional Ergonomist by Japan Ergonomics Society (JES), a member of IEEE ITS Society, and a board member of the Society of Automotive Engineers of Japan (JSAE). 

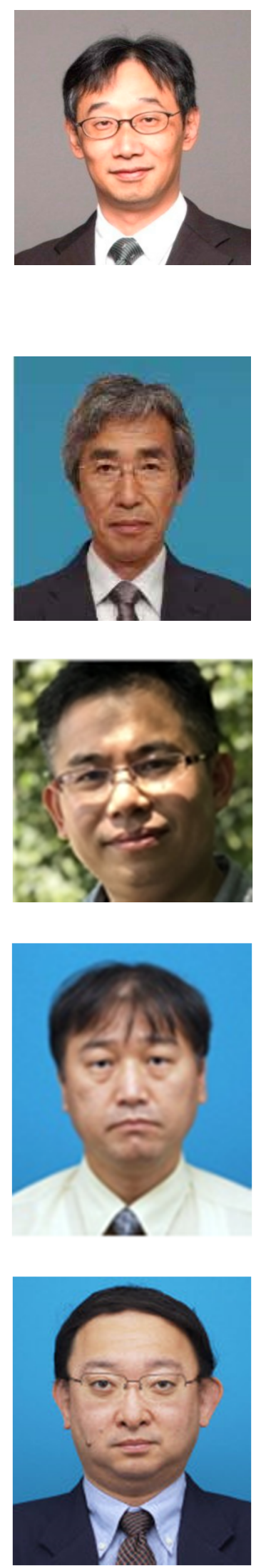

Tatsuya Suzuki was born in Aichi, Japan, in 1964. He received the B.S., M.S. and Ph.D. degrees in Electronic Mechanical Engineering from Nagoya University, Japan in 1986, 1988 and 1991, respectively. Currently, he is a Professor of the Department of Mechanical Systems Engineering, Vice Dean of Graduate School of Engineering, Executive Director of Global Research Institute for Mobility in Society (GREMO), Nagoya University. Dr. Suzuki won the best paper award in International Conference on Autonomic and Autonomous Systems 2017 and the outstanding paper award in International Conference on Control Automation and Systems 2008. He also won the journal paper award from IEEJ, SICE and JSAE in 1995, 2009 and 2010, respectively. His current research interests are in the areas of analysis and design of humancentric intelligent mobility systems, and integrated design of transportation and smart grid systems. Dr. Suzuki is a member of the SICE, ISCIE, IEICE, JSAE, RSJ, JSME, IEEJ and IEEE.

Sueharu Nagiri was born in Nagasaki, Japan in 1956. He received his B.S. degrees from Osaka Prefecture University in 1980. In April 1980, Mr. Nagiri joined Toyota Central R\&D Labs, where he conducted research on preventive safety technologies, particularly the development of driving simulators and the use of these simulators to study drivers' driving behavior. In March 2021, he moved from Toyota Central R\&D Labs to Nagoya University, where he is conducting research on pedestrian, bicycle and car safety at the Institute of Innovation for Future Society.

Quy Hung Nguyen Van was born in Hanoi, Vietnam. He received a Ph.D. degree of Information Aided Technology in Controls Systems from Toyota Technological Institute, Japan in 2002. He is working at Higashi-Fuji Technical Center, Toyota Motor Corporation, Japan in the field of ADAS control systems. His current research interests include Human-Machine Interaction Controls, Driver Risk Perception Modelling, Driving Simulators, etc.

Shouji Itou is working at Higashi-Fuji Technical Center, Toyota Motor Corporation, Japan in the field of ADAS control systems.

Akira Hattori is working at Higashi-Fuji Technical Center, Toyota Motor Corporation, Japan in the field of ADAS control systems. 